\title{
Penerapan Profile Matching di Dalam Aplikasi Penyedia Jasa
}

\author{
Jonathan Christie \\ Program Studi Teknik Informatika \\ Fakultas Teknologi Informasi \\ Universitas Kristen Maranatha \\ jo70ch@gmail.com
}

\author{
Tiur Gantini \\ Program Studi Sistem Informasi \\ Fakultas Teknologi Informasi \\ Universitas Kristen Maranatha \\ tiur.gantini@it.maranatha.edu
}

\begin{abstract}
Abstrak - Penelitian ini bertujuan untuk menyelesaikan masalah terhadap suatu keputusan yaitu di dalam pemilihan penyedia jasa bagi para pengguna jasa. Jasa yang disediakan adalah jasa pembuatan aplikasi (software). Metode yang digunakaan adalah metode profile matching, hal pertama yang dilakukan adalah menentukan kriteria yang akan dinilai untuk pemetaan GAP kompetensi dari setiap penyedia jasa, kemudian menentukan aspek-aspek yang akan digunakan di dalam memproses nilai penyedia jasa. Nilai penyedia jasa tersebut selanjutnya diubah berdasarkan pemetaan GAP kompetensi penyedia jasa. Terdapat dua parameter penting dalam metode ini seperti faktor inti dan faktor sekunder. Nilai-nilai ini diubah menjadi persentase sehingga menghasilkan keputusan akhir sebagai penentu data yang akan lebih dekat dengan target yang telah ditentukan. Dengan melakukan metode ini, menyortir data terhadap kriteria tertentu dapat dilakukan secara dinamis dan dikarenakan metode profile matching menggunakan sistem ranking, maka sistem dapat menampilkan penyedia jasa berdasarkan ranking tertinggi. Dengan menampilkan penyedia jasa berdasarkan ranking tertinggi, penerima jasa dapat lebih mudah untuk menemukan penyedia jasa terbaik.
\end{abstract}

Kata Kunci: Jasa, Keputusan, Penyedia Jasa, Profile Matching, Ranking.

\section{PENDAHULUAN}

Profile matching merupakan metode rekomendasi yang banyak digunakan saat ini. Beberapa penerapan metode profile matching antara lain adalah penerapan di dalam sistem pendukung keputusan penilaian kinerja karyawan pada PT. Hyundai Mobil Indonesia Cabang Kalimalang [1], Pengangkatan jabatan [2], pemberian rekomendasi bagi mahasiswa yang berhak mendapatkan beasiswa [3], sistem pendukung keputusan untuk kenaikan jabatan di PT. Industri Kemasan Semen Gresik [4], profile matching di dalam penyelesaian masalah mengenai penentuan ranking [5], dan masih banyak lagi penelitian yang menerapkan metode ini.

Aplikasi penyedia jasa adalah sebuah aplikasi yang menyediakan jasa bagi para pengguna jasa, yang dibatasi untuk jasa pembuatan aplikasi (software). Setiap pengguna jasa dapat mencari penyedia jasa pembuat aplikasi yang sesuai dengan kebutuhan mereka. Hasil pencarian tersebut memungkinkan untuk menampilkan penyedia jasa yang tidak sesuai dengan harapan penerima jasa. Oleh karena itu, aplikasi penyedia jasa menambahkan sebuah fitur penerapan metode profile matching, agar dapat menghasilkan penyedia jasa terbaik bagi para pencari jasa.

\section{METODOLOGI PENELITIAN}

Metodologi penelitian yang dilakukan adalah dengan menerapkan:

1. Menentukan kebutuhan dan analisis (requirement dan analisis) yaitu menentukan kriteria yang akan digunakan di dalam sistem profile matching.

2. Merancang sistem (design) menentukan nilai untuk setiap kriteria, merancang alur kerja sistem terkait profile matching.

3. Implementasi yaitu menerapkan hasil analisis dan rancangan ke dalam program dengan menggunakan bahasa pemrograman PHP, dan data disimpan di dalam basis data dengan menggunakan PHP MyAdmin.

Sumber data dari penelitian diperoleh dengan metodemetode sebagai berikur:

a. Observasi: pengumpulan data dengan melakukan pengamatan langsung terhadap obyek yang diteliti dengan studi kasus terkait yaitu mengenai penyedia jasa.

b. Studi pustaka: dengan mempelajari jurnal dan sumbersumber buku yang berkaitan dengan acuan teori dalam mendukung penulisan penelitian ilmiah ini.

c. Wawancara: melakukan tanya jawab dengan narasumber penyedia jasa terkait hasil observasi dan studi pustaka yang telah dilakukan.

\section{LANDASAN TEORI}

\section{A. Profile Matching}

Profile matching merupakan proses membandingkan antara kompetensi individu ke dalam kompetensi yang dituju sehingga dapat diketahui perbedaan kompetensinya (disebut GAP), semakin kecil GAP maka bobot nilainya semakin besar. Dengan bobot nilai yang semakin besar maka semakin besar peluang seorang individu untuk mendapatkan urutan 
teratas. Software profile matching yang berfungsi sebagai alat bantu untuk mempercepat proses matching antara profile individu dengan kompetensi yang harus dipenuhi sehingga dapat memperoleh informasi lebih cepat, baik untuk mengetahui gap kompetensi antara jabatan dengan pemegang jabatan maupun dalam pemilihan kandidat yang paling sesuai untuk suatu jabatan (ranking kandidat) [1][2][3].

Langkah-langkah pada metode profile matching yaitu [1][2][3][4][5]:

1. Menentukan variabel-variabel pemetaan GAP kompetensi.

2. Menentukan aspek-aspek yang akan digunakan dalam memproses nilai karyawan.

3. Menghitung hasil pemetaan GAP kompetensi.

GAP yang dimaksud disini adalah perbedaan antara profil karyawan dengan profil standar yang diharapkan atau dapat ditunjukkan pada rumus:

\section{GAP $=$ Profil Karyawan - Profil Standar}

\section{B. Penelitian Terkait Profile Matching}

Telah banyak ditemukan bahwa penerapan profile matching telah dilakukan di dalam berbagai penelitian, antara lain:

1. Penerapan metode profile matching dalam sistem pendukung keputusan penilaian kinerja karyawan pada PT. Hyundai Mobil Indonesia Cabang Kalimalang, terutama dalam kegiatan organisasi dan manajemen sumber daya manusia, sumber daya manusia yang baik akan berdampak positif untuk perkembangan dan kemajuan organisasi atau perusahaan [1].

2. Metode profile matching dan analisis GAP diterapkan di dalam pembahasan mengenai analisa Aspek Kapasitas Intelektual, Aspek Sikap Kerja, dan Aspek Perilaku yang dikategorikan dalam core factor dan secondary factor. Hasil penerapan metode ini berupa sebuah sistem pendukung keputusan yang mampu memberikan evaluasi kinerja pegawai yang akan dipromosikan di PT. Ayn [2].

3. Penerapan metode profile matching dalam penelitian ini digunakan untuk memberikan rekomendasi mahasiswa yang berhak mendapatkan berdasarkan ranking. Variabel yang digunakan adalah IPK, penghasilan orang tua, tanggungan orang tua, dan semester. Untuk core factor atribut: IPK, penghasilan orang tua, sedangkan untuk secondary factor atribut: tanggungan orang tua, dan semester. Untuk perankingan menggunakan $60 \%$ untuk core factor dan $40 \%$ untuk secondary factor [3].

4. Proses profile matching dilakukan untuk menentukan rekomendasi karyawan dalam sistem kenaikan jabatan dan perencanaan karir berdasar pada 3 variabel yaitu pengetahuan dan budaya perusahaan, kemampuan, serta kepribadian. Hasil dari proses seleksi berupa skor akhir karyawan sebagai rekomendasi bagi pengambil keputusan untuk memilih karyawan yang cocok pada jabatan yang kosong tersebut [4].

5. Penerapan profile matching di dalam menyelesaikan masalah pengurutan (ranking) dinamis. Di dalam penelitian ini parameter dikumpulkan sebagai aspek persyaratan utama untuk melakukan perhitungan. Hasil perhitungan yang memiliki akurasi tinggi, perbedaannya kurang cenderung membentuk pola yang berbeda urutan sehingga dapat menghindari kemungkinan data memiliki nilai yang sama [5].

\section{HASIL DAN PEMBAHASAN}

Sebelum dilakukan implementasi program, perlu dilakukan analisa dan desain sistem untuk mempermudah implementasi program karena sebagai acuan untuk menghasilkan program yang baik.

\section{A. Activity Diagram Profile Matching}

Gambar 1 merupakan activity diagram sebagai dasar penggunaan metode profile matching dalam aplikasi penyedia jasa. User yang menggunakan metode profile matching adalah penerima jasa. Untuk menggunakan metode profile matching, penerima jasa menekan tombol jenis jasa. Lalu sistem akan melakukan berbagai perhitungan, dan kemudian menampilkan penyedia jasa sesuai dengan urutan ranking yang ada.

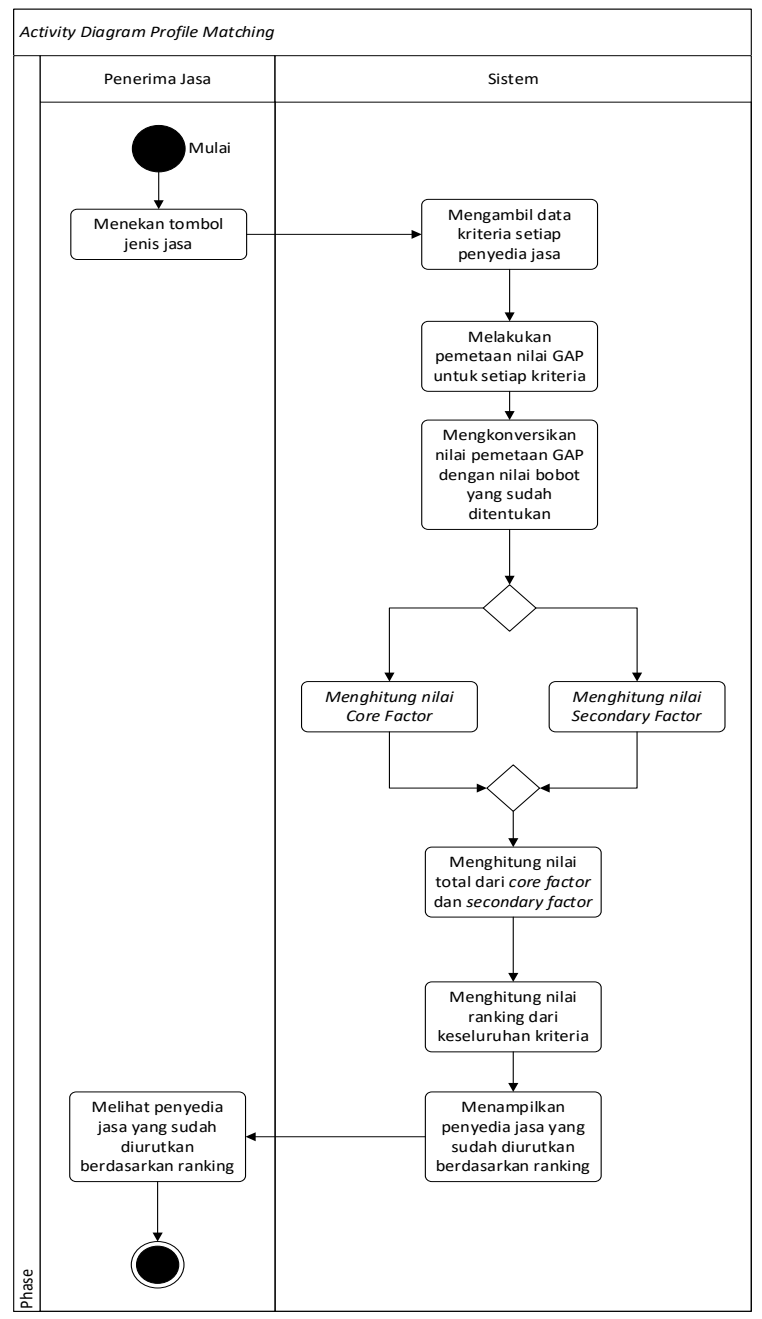

Gambar 1. Activity Diagram Metode Profile Matching. 
B. Penerapan Langkah-Langkah Metode Profile Matching

Metode profile matching dijalankan sistem sesuai dengan rancangan pada activity diagram. Berikut adalah langkahlangkah yang dijalankan sistem untuk menghasilkan ranking:

1. Menentukan Aspek Penilaian dari Setiap Penyedia Jasa

Berdasarkan hasil wawancara, maka aspek penilaian yang diperhitungkan dari setiap penyedia jasa adalah intelektual, penghambat dan perilaku. Masing-masing aspek diturunkan lagi menjadi aspek yang lebih rinci. Aspek intelektual terdiri dari analisis, pembuatan program dan tampilan program. Aspek penghambat terdiri dari pekerjaan terakhir, jumlah pekerjaan bulan ini, dan penolakan perkerjaan. Sedangkan aspek perilaku terdiri dari tanggung jawab, kejujuran dan kelalaian.

Dengan adanya semua aspek penilaian tersebut, diperlukan sebuah penilaian dan bobot penilaianya terhadap setiap aspeknya, Tabel 1 merupakan penilaian kriteria termasuk dengan bobotnya terdiri dari:

Tabel 1. Penilaian Kriteria.

\begin{tabular}{ll}
\hline \multirow{4}{*}{ Nilai Kriteria } & $0=$ Tidak memenuhi syarat \\
\cline { 2 - 2 } 1 = Sangat Kurang \\
\cline { 2 - 2 } 2 = Kurang \\
\hline $3=$ Cukup \\
\hline $4=$ Baik \\
\hline $5=$ Sangat Baik \\
\hline
\end{tabular}

\section{Perhitungan Pemetaan GAP}

Tabel 2, Tabel 3, dan Tabel 4 adalah contoh perhitungan selisih nilai masing-masing kriteria dengan nilai target yang disebut dengan GAP.

Tabel 2 merupakan perhitungan kriteria untuk aspek intelektual. Kriteria yang diperhitungkan pada tabel ini adalah kemampuan analisis, proses pembuatan program, dan juga tampilan dari aplikasi yang dihasilkan. Penilaian tersebut selanjutnya diselesihkan dengan target yang sudah ditentukan, sehingga mengasilkan nilai selisihpada baris yang berada dibawah baris target.

Tabel 2. Perhitungan GAP untuk Aspek Intelektual.

\begin{tabular}{lrrr}
\hline $\begin{array}{l}\text { Nama } \\
\text { Penyedia Jasa }\end{array}$ & Analisis & $\begin{array}{l}\text { Pembuatan } \\
\text { Program }\end{array}$ & Tampilan \\
\hline Alex Network & 4 & 5 & 2 \\
\hline Arif Store & 4 & 3 & 4 \\
\hline KangNetwork & 3 & 4 & 3 \\
\hline Penghubung & 4 & 4 & 3 \\
\hline Target & 3 & 3 & 3 \\
\hline Alex Network & 1 & 2 & -1 \\
\hline Arif Store & 1 & 0 & 1 \\
\hline Kang Network & 0 & 1 & 0 \\
\hline Penghubung & 1 & 1 & 0 \\
\hline
\end{tabular}

Tabel 3 merupakan perhitungan kriteria untuk aspek penghambat. Kriteria yang diperhitungkan pada tabel ini adalah pekerjaan terakhir yang dikerjakan, jumlah pekerjaan yang sudah dikerjakan dalam satu bulan, dan juga jumlah pekerjaan yang ditolak dalam satu bulan terakhir. Penilaian aspek penghambat digunakan untuk membantu pemerataan pekerjaan pada aplikasi penyedia jasa. Penilaian tersebut selanjutnya diselesihkan dengan target yang sudah ditentukan, sehingga mengasilkan nilai selisih pada baris yang berada dibawah baris target.

Tabel 3. Perhitungan GAP untuk Aspek Penghambat.

\begin{tabular}{lrrr}
\hline $\begin{array}{c}\text { Nama } \\
\text { Penyedia } \\
\text { Jasa }\end{array}$ & $\begin{array}{c}\text { Pekerjaan } \\
\text { Terakhir }\end{array}$ & $\begin{array}{c}\text { Jumlah } \\
\text { Pekerjaan } \\
\text { bulan Ini }\end{array}$ & $\begin{array}{c}\text { Penolakan } \\
\text { pekerjaan }\end{array}$ \\
\hline Alex Network & 1 & 3 & 4 \\
\hline Arif Store & 4 & 5 & 4 \\
\hline KangNetwork & 2 & 2 & 5 \\
\hline Penghubung & 1 & 0 & 3 \\
\hline Target & 4 & 4 & 3 \\
\hline Alex Network & -3 & -1 & 1 \\
\hline Arif Store & 0 & 1 & 1 \\
\hline Kang Network & -2 & -2 & 2 \\
\hline Penghubung & -3 & -4 & 0 \\
\hline
\end{tabular}

Tabel 4 merupakan perhitungan kriteria untuk aspek perilaku. Sesudah penerima jasa menerima jasa yang diberikan oleh penyedia jasa, penerima jasa diminta untuk memasukan penilaian terhadap perilaku penyedia jasa. Kriteria yang diperhitungkan pada tabel ini adalah tanggung jawab dari jasa yang dikerjakan, kejujuran, dan juga kelalaian penyedia jasa. Penilaian tersebut selanjutnya diselesihkan dengan target yang sudah ditentukan, sehingga mengasilkan nilai selisih pada baris yang berada dibawah baris target.

Tabel 4. Perhitungan GAP untuk Aspek Perilaku.

\begin{tabular}{lrrr}
\hline $\begin{array}{c}\text { Nama } \\
\text { Penyedia Jasa }\end{array}$ & $\begin{array}{c}\text { Tanggung } \\
\text { Jawab }\end{array}$ & Kejujuran & Kelalaian \\
\hline Alex Network & 5 & 4 & 5 \\
\hline Arif Store & 4 & 4 & 4 \\
\hline KangNetwork & 2 & 3 & 5 \\
\hline Penghubung & 4 & 5 & 4 \\
\hline Target & 3 & 4 & 4 \\
\hline Alex Network & 2 & 0 & 1 \\
\hline Arif Store & 1 & 0 & 0 \\
\hline Kang Network & -1 & -1 & 1 \\
\hline Penghubung & 1 & 1 & 0 \\
\hline
\end{tabular}

\section{Pembobotan GAP}

Sesudah melakukan perhitungan pemetaan GAP diatas, selajutnya adalah pembobotan GAP. Tabel 5 adalah tabel bobot penilaian GAP. Bobot penilaian GAP digunakan sebagai dasar untuk merubah nilai selisih hasil perhitungan GAP menjadi nilai bobot. 
Tabel 5. Tabel Bobot Nilai GAP.

\begin{tabular}{crl}
\hline Selisih & $\begin{array}{c}\text { Bobot } \\
\text { Nilai }\end{array}$ & \multicolumn{1}{c}{ Keterangan } \\
\hline 0 & 5 & $\begin{array}{l}\text { Tidak ada selisih (kompetensi } \\
\text { sesuai dengan yang } \\
\text { dibutuhkan) }\end{array}$ \\
\hline 1 & 4,5 & $\begin{array}{l}\text { Kompetensi individu kelebihan } \\
1 \text { tingkat }\end{array}$ \\
\hline-1 & 4 & $\begin{array}{l}\text { Kompetensi individu } \\
\text { kekurangan 1 tingkat }\end{array}$ \\
\hline 2 & 3,5 & $\begin{array}{l}\text { Kompetensi individu kelebihan } \\
\text { 2 tingkat }\end{array}$ \\
\hline-2 & 3 & $\begin{array}{l}\text { Kompetensi individu } \\
\text { kekurangan 2 tingkat }\end{array}$ \\
\hline 3 & 2,5 & $\begin{array}{l}\text { Kompetensi individu kelebihan } \\
\text { tingkat }\end{array}$ \\
\hline-3 & 2 & $\begin{array}{l}\text { Kompetensi individu } \\
\text { kekurangan 3 tingkat }\end{array}$ \\
\hline 4 & 1,5 & $\begin{array}{l}\text { Kompetensi individu kelebihan } \\
\text { 4 tingkat }\end{array}$ \\
\hline-4 & 1 & $\begin{array}{l}\text { Kompetensi individu } \\
\text { kekurangan 4 tingkat }\end{array}$ \\
\hline
\end{tabular}

Nilai selisih yang didapatkan oleh setiap penyedia jasa pada ketiga aspek yang diperhitungkan, yaitu aspek intelektual, aspek penghambat, dan aspek perilaku selanjutnya dirubah menjadi nilai bobot. Tabel 6, Tabel 7, dan Tabel 8 merupakan pembobotan dari ketiga aspek yang diperhitungkan. Hasil selisih yang bernilai 0, maka mendapatkan bobot nilai 5. Hasil selisih yang mendapatkan nilai 1 akan mendapatkan bobot nilai 4,5. Hasil selisih tersebut dikonversikan menjadi bobot nilai berdasarkan tabel bobot nilai GAP. Hasil konversi nilai selisih menjadi bobot nilai dapat dilihat pada baris dibawah baris yang diberi warna hijau.

Tabel 6. Aspek Intelektual hasil pemetaan GAP dan hasil bobot nilai GAP.

\begin{tabular}{lrrr}
\hline $\begin{array}{c}\text { Nama } \\
\text { Penyedia Jasa }\end{array}$ & Analisis & $\begin{array}{c}\text { Pembuatan } \\
\text { Program }\end{array}$ & Tampilan \\
\hline Alex Network & 1 & 2 & -1 \\
\hline Arif Store & 1 & 0 & 1 \\
\hline KangNetwork & 0 & 1 & 0 \\
\hline Penghubung & 1 & 1 & 0 \\
\hline & & & \\
\hline Alex Network & 4.5 & 3.5 & 4 \\
\hline Arif Store & 4.5 & 5 & 4.5 \\
\hline Kang Network & 5 & 4.5 & 5 \\
\hline Penghubung & 4.5 & 4.5 & 5 \\
\hline
\end{tabular}

Tabel 7. Aspek Penghambat hasil pemetaan GAP dan hasil bobot nilai GAP.

\begin{tabular}{lrrr}
\hline $\begin{array}{c}\text { Nama } \\
\text { Penyedia Jasa }\end{array}$ & $\begin{array}{c}\text { Pekerjaan } \\
\text { Terakhir }\end{array}$ & $\begin{array}{c}\text { Jumlah } \\
\text { Pekerjaan } \\
\text { Bulan Ini }\end{array}$ & $\begin{array}{c}\text { Penolakan } \\
\text { pekerjaan }\end{array}$ \\
\hline Alex Network & -3 & -1 & 1 \\
\hline Arif Store & 0 & 1 & 1 \\
\hline KangNetwork & -2 & -2 & 2 \\
\hline Penghubung & -3 & -4 & 0 \\
\hline & & & \\
\hline Alex Network & 2 & 4 & 4.5 \\
\hline Arif Store & 5 & 4.5 & 4.5 \\
\hline Kang Network & 3 & 3 & 3.5 \\
\hline Penghubung & 2 & 1 & 5 \\
\hline
\end{tabular}

Tabel 8. Aspek Perilaku hasil pemetaan GAP dan hasil bobot nilai GAP.

\begin{tabular}{lrrr}
\hline $\begin{array}{c}\text { Nama } \\
\text { Penyedia Jasa }\end{array}$ & \multicolumn{1}{c}{$\begin{array}{c}\text { Tanggung } \\
\text { Jawab }\end{array}$} & Kejujuran & Kelalaian \\
\hline Alex Network & 2 & 0 & 1 \\
\hline Arif Store & 1 & 0 & 0 \\
\hline KangNetwork & -1 & -1 & 1 \\
\hline Penghubung & 1 & 1 & 0 \\
\hline & & & \\
\hline Alex Network & 3.5 & 5 & 4.5 \\
\hline Arif Store & 4.5 & 5 & 5 \\
\hline Kang Network & 4 & 4 & 4.5 \\
\hline Penghubung & 4.5 & 4.5 & 5 \\
\hline
\end{tabular}

4. Perhitungan Core Factor dan Secondary Factor

Sesudah menentukan bobot nilai GAP untuk setiap aspek yang dinilai, aspek tersebut dikelompokan menjadi dua kelompok, yaitu core factor dan secondary factor. Core Factor dan Secondary Factor untuk aspek intelektual dihitung menggunakan rumus NFC dan NSF, kemudian hasilnya dapat dilihat pada kolom NFC dan NSF pada Tabel 9, Tabel 10, dan Tabel 11. Berikut adalah contoh pengerjaan perhitungan NFC dan NSF terhadap penyedia jasa Alex Network:

$$
\begin{array}{ll}
\mathrm{NFC}=\frac{\sum \mathrm{Ne}}{\sum \mathrm{Ic}} & \mathrm{NFC}=\frac{4.5+9.5}{2}=4.25 \\
\mathrm{NSF}=\frac{\sum \mathrm{Ns}}{\sum \mathrm{Is}} & \mathrm{NSF}=\frac{4}{1}=4
\end{array}
$$


Tabel 9. Pengelompokkan Bobot Nilai GAP Aspek Intelektual.

\begin{tabular}{lrrrrr}
\hline Nama Penyedia Jasa & Analisis & $\begin{array}{c}\text { Pembuatan } \\
\text { Program }\end{array}$ & Tampilan & NFC & NSF \\
\hline Alex Network & 4.5 & 3.5 & 4 & 4 & 4 \\
\hline Arif Store & 4.5 & 5 & 4.5 & 4.75 & 4.5 \\
\hline Kang Network & 5 & 4.5 & 5 & 4.75 & 5 \\
\hline Penghubung & 4.5 & 4.5 & 5 & 4.5 & 5 \\
\hline
\end{tabular}

Tabel 10. Pengelompokkan Bobot Nilai GAP Aspek Penghambat.

\begin{tabular}{lrrrrr}
\hline $\begin{array}{c}\text { Nama Penyedia } \\
\text { Jasa }\end{array}$ & $\begin{array}{c}\text { Pekerjaan } \\
\text { Terakhir }\end{array}$ & $\begin{array}{c}\text { Jumlah } \\
\text { Pekerjaan } \\
\text { Bulan Ini }\end{array}$ & $\begin{array}{c}\text { Penolakan } \\
\text { pekerjaan }\end{array}$ & NFC & NSF \\
\hline Alex Network & 2 & 4 & 4.5 & 3 & 4.5 \\
\hline Arif Store & 5 & 4.5 & 4.5 & 4.75 & 4.5 \\
\hline Kang Network & 3 & 3 & 3.5 & 3 & 3.5 \\
\hline Penghubung & 2 & 1 & 5 & 1.5 & 5 \\
\hline
\end{tabular}

Tabel 11. Pengelompokkan Bobot Nilai GAP Aspek Perilaku.

\begin{tabular}{lrrrrr}
\hline Nama Penyedia Jasa & $\begin{array}{c}\text { Tanggung } \\
\text { Jawab }\end{array}$ & Kejujuran & Kelalaian & NFC & NSF \\
\hline Alex Network & 3.5 & 5 & 4.5 & 4.25 & 4.5 \\
\hline Arif Store & 4.5 & 5 & 5 & 4.75 & 5 \\
\hline Kang Network & 4 & 4 & 4.5 & 4 & 4.5 \\
\hline Penghubung & 4.5 & 4.5 & 5 & 4.5 & 5 \\
\hline
\end{tabular}

\section{Perhitungan Nilai Total}

Berdasarkan hasil perhitungan setiap aspek, berikut proses perhitungan nilai total berdasarkan presentase dari core factor dan secondary factor yang diperkirakan berpengaruh. Berikut contoh perhitungan nilai total untuk penyedia jasa Alex Network.

Nilai total $=(\mathrm{X}) \% \mathrm{NCF}+(\mathrm{X}) \% \mathrm{NSF}$

Nilai total $=(70 \% 4)+(30 \% 4)$

$$
\begin{aligned}
& =2.8+1.2 \\
& =4
\end{aligned}
$$

Kolom Nilai total pada Tabel 12, Tabel 13, dan Tabel 14 merupakan nilai hasil perhitungan nilai total masing-masing penyedia jasa.

Tabel 12 Nilai Total Aspek Intelektual.

\begin{tabular}{lrrr}
\hline Nama Penyedia Jasa & \multicolumn{1}{c}{ NFC } & \multicolumn{1}{c}{ NSF } & Nilai Total \\
\hline Alex Network & 4 & 4 & 4 \\
\hline Arif Store & 4.75 & 4.5 & 4.675 \\
\hline Kang Network & 4.75 & 5 & 4.825 \\
\hline Penghubung & 4.5 & 5 & 4.65 \\
\hline
\end{tabular}

Tabel 13 Nilai Total Aspek Penghambat.

\begin{tabular}{lrrr}
\hline Nama Penyedia Jasa & \multicolumn{1}{c}{ NFC } & NSF & Nilai Total \\
\hline Alex Network & 3 & 4.5 & 3.45 \\
\hline Arif Store & 4.75 & 4.5 & 4.675 \\
\hline Kang Network & 3 & 3.5 & 3.15 \\
\hline Penghubung & 1.5 & 5 & 2.55 \\
\hline
\end{tabular}

Tabel 14 Nilai Total Aspek Perilaku.

\begin{tabular}{lrrr}
\hline Nama Penyedia Jasa & NFC & NSF & \multicolumn{1}{c}{ Nilai Total } \\
\hline Alex Network & 4.25 & 4.5 & 4.325 \\
\hline Arif Store & 4.75 & 5 & 4.825 \\
\hline Kang Network & 4 & 4.5 & 4.15 \\
\hline Penghubung & 4.5 & 5 & 4.65 \\
\hline
\end{tabular}

6. Perhitungan Penentuan Ranking

Hasil akhir dari proses profile matching adalah ranking. Sebagai contoh perhitungan ranking penyedia jasa Alex Network sebagai berikut:

$$
\begin{aligned}
\text { Ranking }= & (\mathrm{X}) \% \mathrm{~N} 1+(\mathrm{X}) \% \mathrm{~N} 2+(\mathrm{X}) \% \mathrm{~N} 3 \\
\text { Ranking }= & (50) \% \mathrm{~N} 1+(20) \% \mathrm{~N} 2+(30) \% \mathrm{~N} 3 \\
= & ((50 / 100) * 4)+((20 / 100) * 3.45) \\
& +((30 / 100) * 4.325) \\
= & 2+0.69+1.2975 \\
= & 3.9875
\end{aligned}
$$


Keterangan:
N1 = Nilai Intelektual
N2 = Nilai Penghambat
N3 = Nilai Perilaku
$(\mathrm{X}) \%=$ Nilai Persen yang diinputkan

Hasil perhitungan ranking dari setiap penyedia jasa dapat dilihat pada Tabel 15. N1, N2, dan N3 merupakan nilai total dari aspek yang diperhitungkan dalam metode profile matching. N1 merupakan aspek intelektual, N2 merupakan aspek penghambat, dan N3 merupakan aspek perilaku.

Tabel 15. Hasil Ranking Metode Profile Matching.

\begin{tabular}{lrrrr}
\hline $\begin{array}{c}\text { Nama } \\
\text { Penyedia Jasa }\end{array}$ & N1 & N2 & N3 & $\begin{array}{c}\text { Nilai } \\
\text { Akhir }\end{array}$ \\
\hline Arif Store & 4.675 & 4.675 & 4.825 & 4.72 \\
\hline Kang Network & 4.825 & 3.15 & 4.15 & 4.2875 \\
\hline Penghubung & 4.65 & 2.55 & 4.65 & 4.23 \\
\hline Alex Network & 4 & 3.45 & 4.325 & 3.9875 \\
\hline
\end{tabular}

Sesudah melakukan perhitungan ranking menggunakan metode profile matching, maka didapatkan nilai akhir dari setiap penyedia jasa seperti Tabel 15. Berdasarkan nilai akhir tersebut, sistem dapat menentukan urutan penyedia jasa yang akan ditampilkan pada tampilan penyedia jasa.

\section{Implementasi Metode Profile Matching}

Metode profile matching diimplementasi pada aplikasi penyedia jasa. Penerima jasa dapat menekan salah satu jenis jasa pada Gambar 2 untuk menampilkan penyedia jasa yang tersedia terhadap jenis jasa tersebut.

\section{SERVICES}

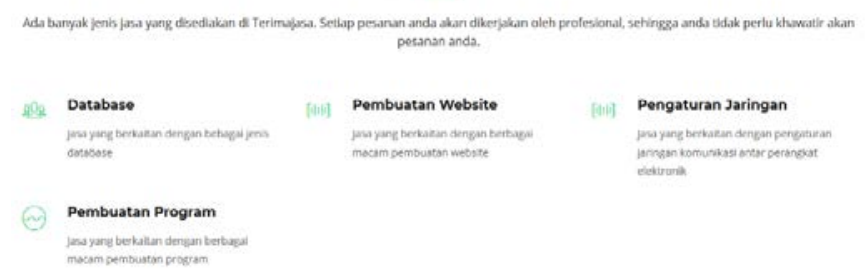

Gambar 2. Tampilan untuk Menampilkan Jenis Jasa

Sesudah menekan salah satu jenis jasa, maka sistem akan melakukan perhitungan metode profile matching. Perhitungan menggunakan metode profile matching tersebut akan memberikan urutan ranking penyedia jasa kepada sistem. Kemudian sistem akan menampilkan penyedia jasa berdasarkan ranking seperti pada Gambar 3.

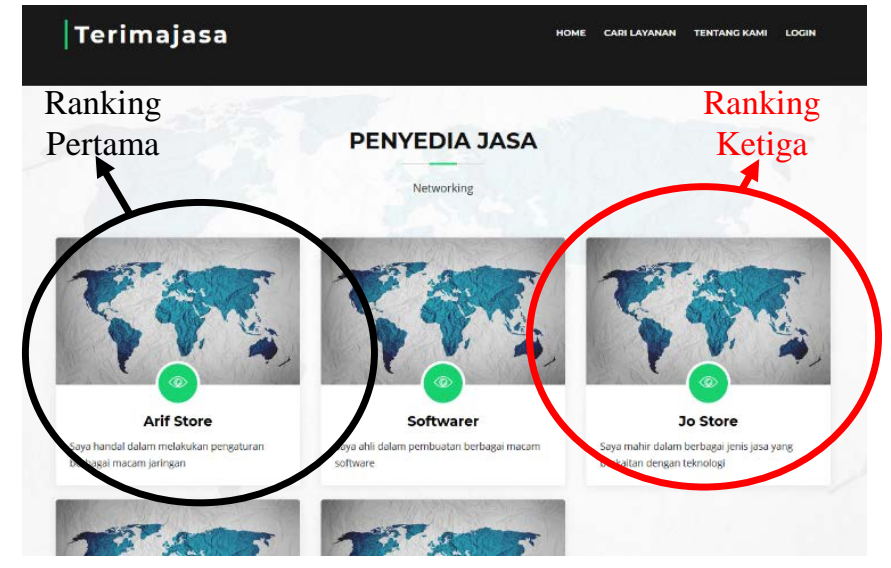

Gambar 3. Tampilan untuk Melihat Penyedia Jasa yang Sudah Diurutkan Berdasarkan Ranking

\section{KESIMPULAN}

Kesimpulan yang dapat diambil dari penerapan metode profile matching pada aplikasi penyedia jasa yaitu metode profile matching diterapkan ke dalam aplikasi penyedia jasa untuk sistem ranking yang akan dikalkulasikan. Sistem ranking diterapkan agar setiap penerima jasa dapat mendapatkan penyedia jasa terbaik. Sistem ranking juga berguna agar semua penyedia jasa yang terdaftar pada aplikasi penyedia jasa dapat mendapatkan pesanan jasa. Ranking yang dihasilkan oleh metode ini berdasarkan dari riwayat penyedia jasa yang akan dikalkulasikan secara terus menerus.

\section{REFERENSI}

[1] Purwanto, H. (2017). Penerapan Metode Profile Matching dalam Sistem Pendukung Keputusan Peniliaian Kinerja Karyawan pada PT. HYUNDAI MOBIL INDONESIA Cabang Kalimalang. Jurnal Techno Nusa Mandiri, Vol. XIV, No. 1, pp. 15-20.

[2] Adhar. (2014). Sistem Pendukung Keputusan Pengangkatan Jabatan. Jatisi, Vol. 1, No. 1, pp. 16-29.

[3] Darmawan, S. (2012). Pemilihan Beasiswa Bagi Mahasiswa STMIK WIDYA PRATAMA. Jurnal Ilmiah ICTech, Vol. X, No. 1, pp. 1-5.

[4] Muqtadir \& Purdianto, I. (2013). Sistem Pendukung Keputusan Kenaikan Jabatan Menggunakan Metode Profile Matching (Studi Kasus di PT. Industri Kemasan Semen Gresik). Seminar Nasional Aplikasi Teknologi Informasi (SNATI). Yogyakarta.

[5] Tharo, Z. \& Siahaan, A.P.U. (2016). Profile Matching in Solving Rank Problem. IOSR Journal of Electronics and Communication Engineering (IOSR-JECE), Vol. 11, No. 5, pp. 73-76. 